\title{
THE CONTINUUM MODELLING OF TWO-PHASE FLOW SYSTEMS
}

\author{
R.T. Lahey, Jr., Co-PI \\ D.A. Drew, Co-PI \\ Rensselaer Polytechnic Institute \\ Troy, New York 12180-3590
}

\section{TABLE OF CONTENTS}

1. Project Description $\ldots \ldots \ldots \ldots \ldots \ldots \ldots \ldots \ldots \ldots \ldots \ldots \ldots \ldots, 1$

2. Research Accomplishments $\ldots \ldots \ldots \ldots \ldots \ldots \ldots \ldots \ldots \ldots \ldots, 1$

3. Proposed Research................................ 3

4. Technical Publications $\ldots \ldots \ldots \ldots \ldots \ldots \ldots \ldots \ldots \ldots \ldots \ldots \ldots, 4$

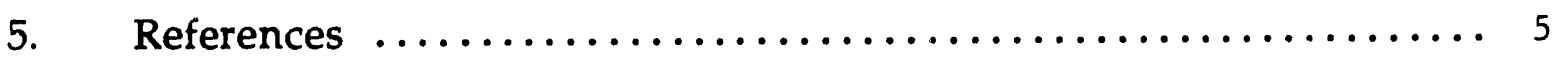

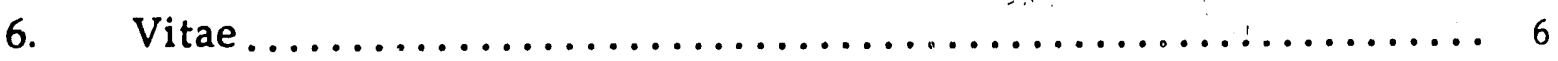

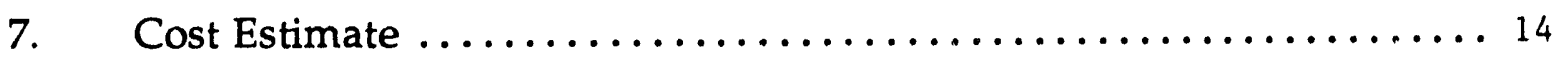

\section{PROJECT DESCRIPTION}

This research program is concerned with the development of self-consistent multidimensional two-fluid models which predict a wide variety of data and satisfy all relevant physical laws and constraints. If successful, these models can revolutionize the way in which two-phase flows are analyzed, since mechanistic, rather than empirical-based predictions should be possible.

\section{RESEARCH ACCOMPLISHMENTS}

During this report period the research has focused on understanding the relationships between the interfacial closure laws and the onset of ill-posedness. In particular, it is now known that only the vioid wave eigenvalues can become 


\section{DISCLAIMER}

This report was prepared as an account of work sponsored by an agency of the United States Government. Neither the United States Government nor any agency thereof, nor any of their employees, makes any warranty, express or implied, or assumes any legal liability or responsibility for the accuracy, completeness, or usefulness of any information, apparatus, product, or process disclosed, or represents that its use would not infringe privately owned rights. Reference herein to any specific commercial product, process, or service by trade name, trademark, manufacturer, or otherwise does not necessarily constitute or imply its endorsement, recommendation, or favoring by the United States Government or any agency thereof. The views and opinions of authors expressed herein do not necessarily state or reflect those of the United States Government or any agency thereof. 
complex, thus leading to ill-posedness. As a consequence, a detailed set of void wave data were taken in the air/oil test facility shown schematically in Fig. 1, and these data were compared with the two-fluid model we have developed. The kinematic void wave data was well predicted, and, in addition, a much faster void wave was also measured. The faster void wave was associated with bubble clusters which were observed to form due to hydrodynamic effects. Significantly, these clusters were found to be the precursors of Taylor bubble formation (ie, the bubblyto-slug flow regime transition). Moreover, it was found that for certain conditions, these void waves were amplified, thus triggering flow regime transition.

A separate analytical and experimental study, summarized in Appendix-I, was completed on lateral phase distribution phenomena. As can be noted in Figs. 2, it was found that, using the same two-fluid model as was used for void waves, the observed lateral phase distribution could be mechanistically predicted in simple and complex geometry conduits. This is a very important finding since it opens the door for many important applications of this CFD-based technique.

Another related study concerned the development of an integrodifferential moment generation equation for evolution of interfacial area density $\left(A_{i}^{\prime \prime \prime}\right)$ and flow regime transition. During the report period, the experimental study summarized in Appendix-II was completed. This research task is nearly complete and is very promising. Indeed, the results to date are completely consistent with our void wave results, and it appears that we may be able to perform, for the first time, completely mechanistic predictions of bubbly-to-slug flow regime transition (eg, see Fig. 3). If so, this will represent a major breakthrough in the field of two-phase flow. 


\section{PROPOSED RESEARCI!}

In accordance with the previously approved four year work scope, the next year of research will be devoted to continuing to advance the state-of-the-art in twofluid modeling. In particular, to extend the multidimensional two-fluid models developed to date to accommodate diabatic heat and mass transfer effects.

In order to address two-phase heat and mass transfer effects (eg, boiling phenomena) we will need to extend the two-fluid model that we have developed.

For example, we will need to constitute models for the interfacial mass, momentum and energy transfers as well as the Marangoni phenomena inherent in the interfacial jump conditions.

It is envisioned that we will first implement relatively simple heat transfer models, such as those used in THERMIT [Kelly and Kazimi, 1982], and once we have sufficient experience with these models, they can be extended and improved to allow us to mechanistically predict some of the key phenomena of interest in diabatic two-phase flow (eg, subcooled boiling and CHF).

In order to guide the development of diabatic closure models, it is proposed that direct numerical simulations be performed for some simple boiling phenomena (ie, wall nucleation and ebullition). That is, the Navier Stokes equations will be simultaneously evaluated for each phase, and an adaptive grid finite element algorithm will be used to track the vapor/liquid interface of a growing vapor bubble. While such numerical simulations are expected to be computer intensive, and expensive,they are needed to give us insight into how to develop macroscopic models of surface-tension-gradient-induced (ie, Marangoni)forces. Such forces are expected to be important for the prediction of the Net Vapor Generation (NVG) point in subcooled boiling and the localized flooding phenomena associated with CHF [Lee et al, 1988]. 
In addition, it is planned that during the next report period, the research associated with the mechanistic prediction of interfacial area density ( $\left.A_{i}^{\prime \prime}\right)$ will be completed and the resultant model implemented as another evolution equation in the multidimensional two-fluid model.

\section{TECHNICAL PUBLICATIONS}

During the report period the following technical reports and publications associated with this project were completed:

\section{Thesis}

"Void Wave Propagation In Two-Phase Flow", RPI Ph.D. Thesis, Jee-Won Park.

"Turbulent Bubbly Two-Phase Flow In A Triangular Duct", RPI Ph.D. Thesis, Martin Lopez de Bertodano.

\section{Books}

"Analytical Modeling of Multiphase Flows", 1992, editor, M.C. Roco, $\underline{\text { Particulate }}$ Two-Phase Flow, Butterworth.

\section{Lournal Articles}

"Analysis of Phase Distribution in Fuily Developed Laminar Bubbly Two-Phase Flow", 1991, International Journal of Multiphase Flow, Vol-17, No 5, pp. 635652.

"An Analysis of the Eigenvalues of Bubbly Two-Phase Flows", 1991,Chemical Engineering Communications, Vol-106, pp. 93-117.

"The Theory of Ensemble Averaging for Two-Phase Flow", 1991, submitted to International Journal of Multiphase Flow.

"A Characteristic Analysis of Void Waves Using Two-Fluid Models," 1991, submitted to International Journal of Multiphase Flow. 
5

"On the Development of Multidimensional Two-fluid Models for Vapor/Liquid Two-Phase Flows", 1991, submitted to Chemical Engineering Communications.

Proceedings

"A Characteristic Analysis of Void Waves Using Two-Fluid Models", 1991, Proceedings of the International Conference on Multiphase Flow, Tsukuba, Japan.

"The Analysis of Phase Distribution in Turbulent Two-Phase Flows", 1991, Proceedings of the 4th International Lecture Course on Waves and Turbulence in Multiphase Flow, and Its Application, Osaka, Japan.

"Multiphase Thermal Science", 1991, Proceedings of the NSF Workshop on Thermal Sciences, Chicago, 1991.

"Turbulent Bubbly Two-Phase Flow in a Triangular Duct", 1992, Proceedings of the 26th NHTC (Appendix-I).

"Interfacial Area Density, Mean Radius and Number Density Measurements in Bubbly Two-Phase Flow", 1992, Proceedings of NURETH-5 (Appendix-II).

5. REFERENCES

Kelly, J.E. and Kazimi, M.S., 1982, "Interfacial Exchange Relations for Two-Fluid Vapor-Liquid Flow: A Simplified Regime-Map Approach", Nuc. Sci. \& Eng. Vol-81, pp. 305-318.

Lee, C.H. and Mudawwar, I., 1988, "A Mechanistic CHF Model for Subcooled Flow Boiling Based on Local Bulk Flow Conditions", Int. I. Multiphase Flow, Vol14, No. 6, pp 711-728.

attacked papers removed and cycled separately- 


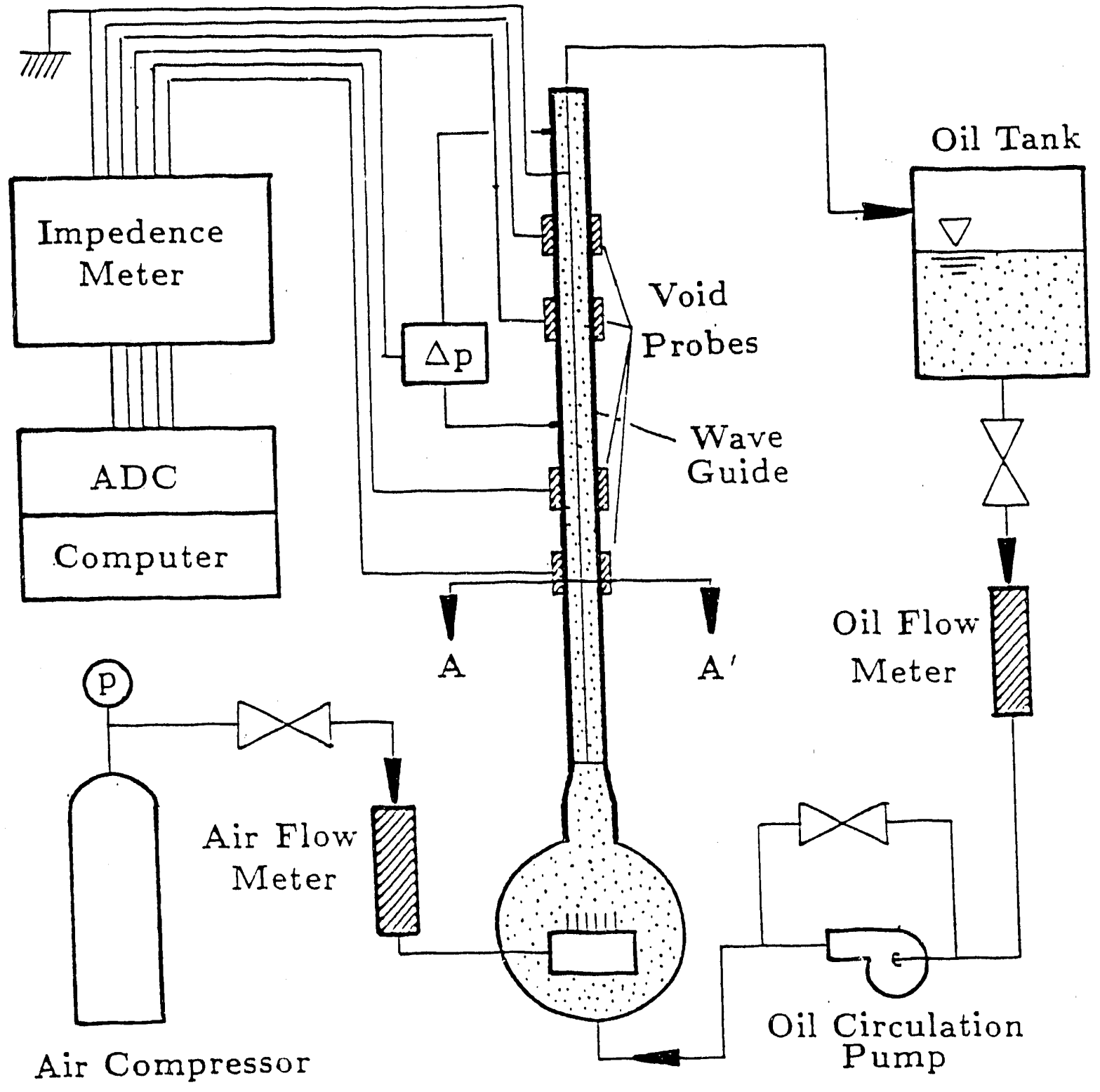

Fig. 1 Void Wave Test Facility 


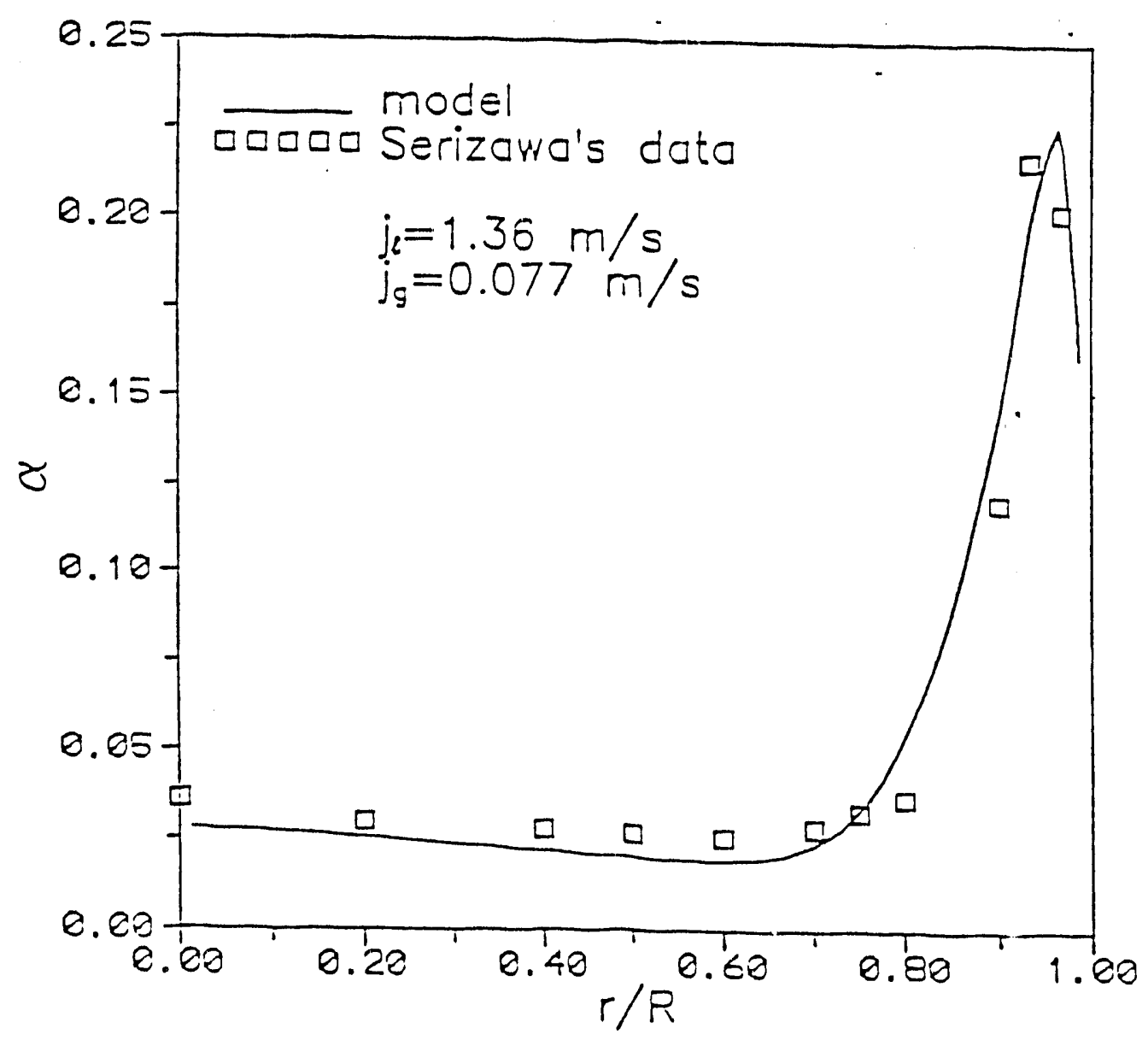

Fig. 2a Void Fraction Comparison with Serizawa's Bubbly Upflow Data: $\left(\mathrm{j}_{\ell}=1.36 \mathrm{~m} / \mathrm{s} ; \mathrm{j}_{\mathrm{g}}=0.077 \mathrm{~m} / \mathrm{s} ; D_{\mathrm{b}}=3 \mathrm{~mm} ; \mathrm{C}_{\mathrm{L}}=1.0 ; \mathrm{C}_{\mathrm{p}}=1.0\right)$ 


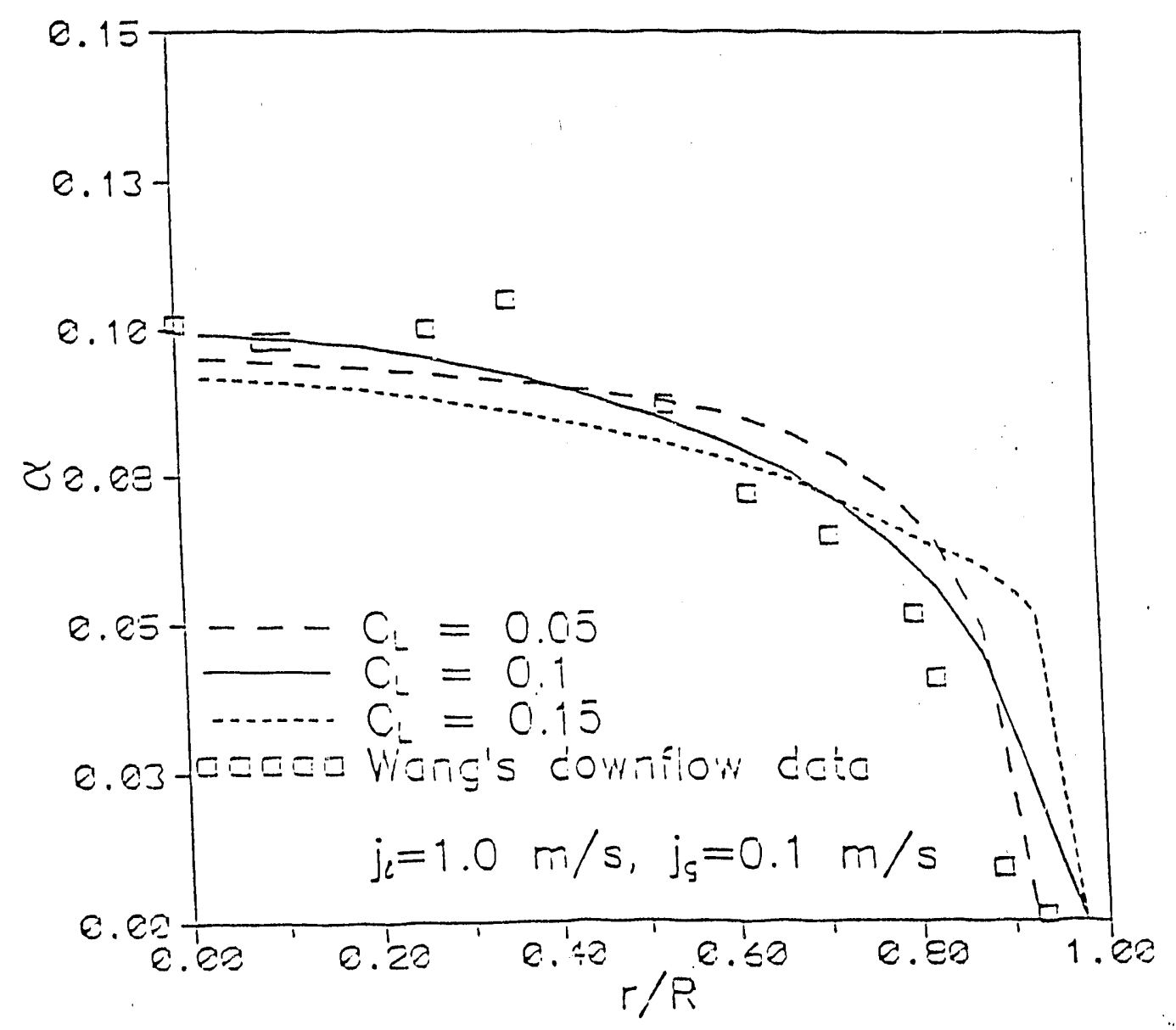

Fig. 2b Void Fraction Comparison with Wang's Bubbly Downflow Data: The Effect of Lift Coefficient, $C_{L}\left(C_{P}=1.0, D_{b}=3 \mathrm{~mm}\right)$ 


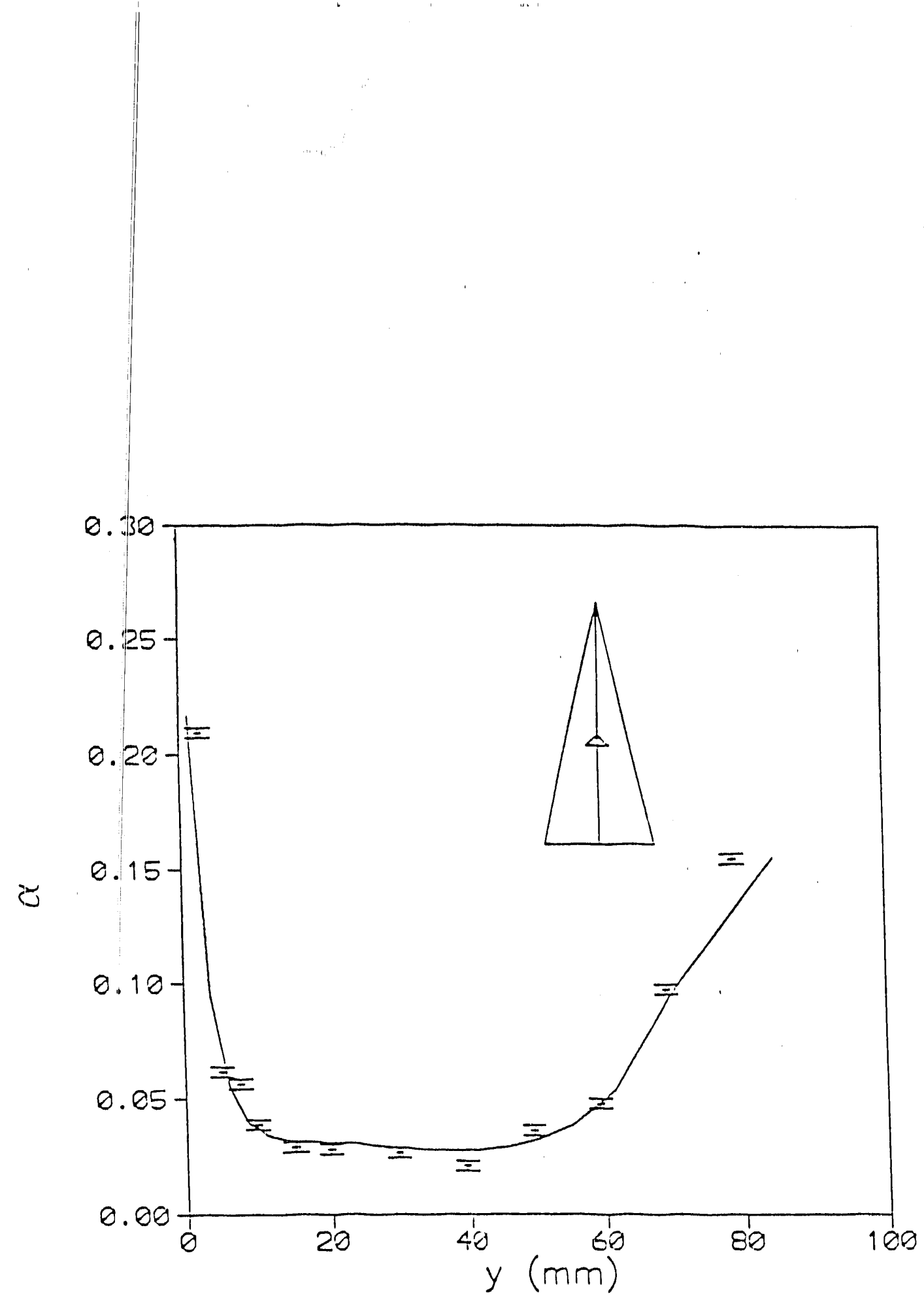

Fig. 2c Void Fraction Comparison with Bubbly Upflow Data In a Triangle $\left(j_{\ell}=1.0 \mathrm{~m} / \mathrm{s} ; j_{g}=0.1 \mathrm{~m} / \mathrm{s} ; C_{L}=0.1 ; C_{p}=1.0\right)$ 


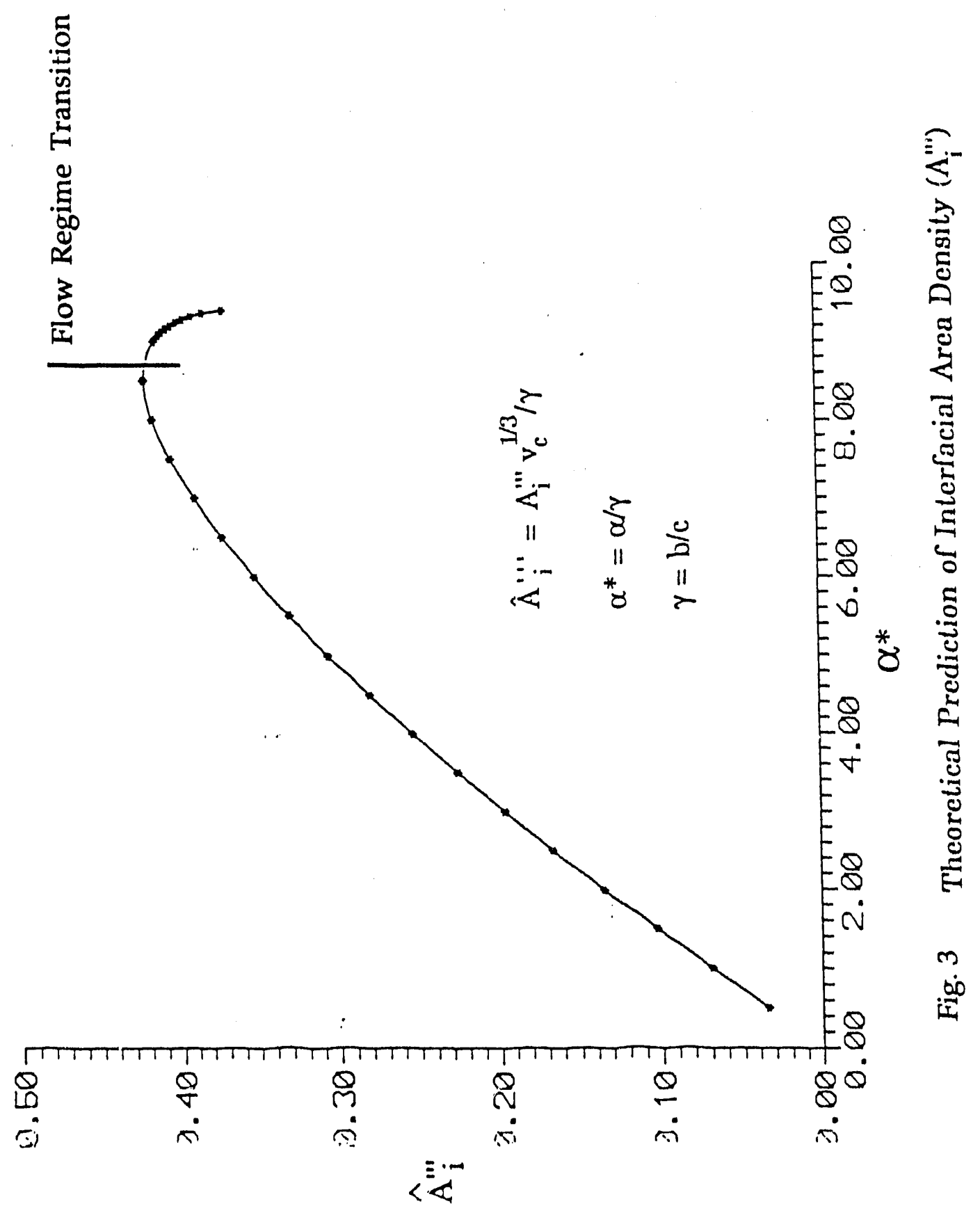



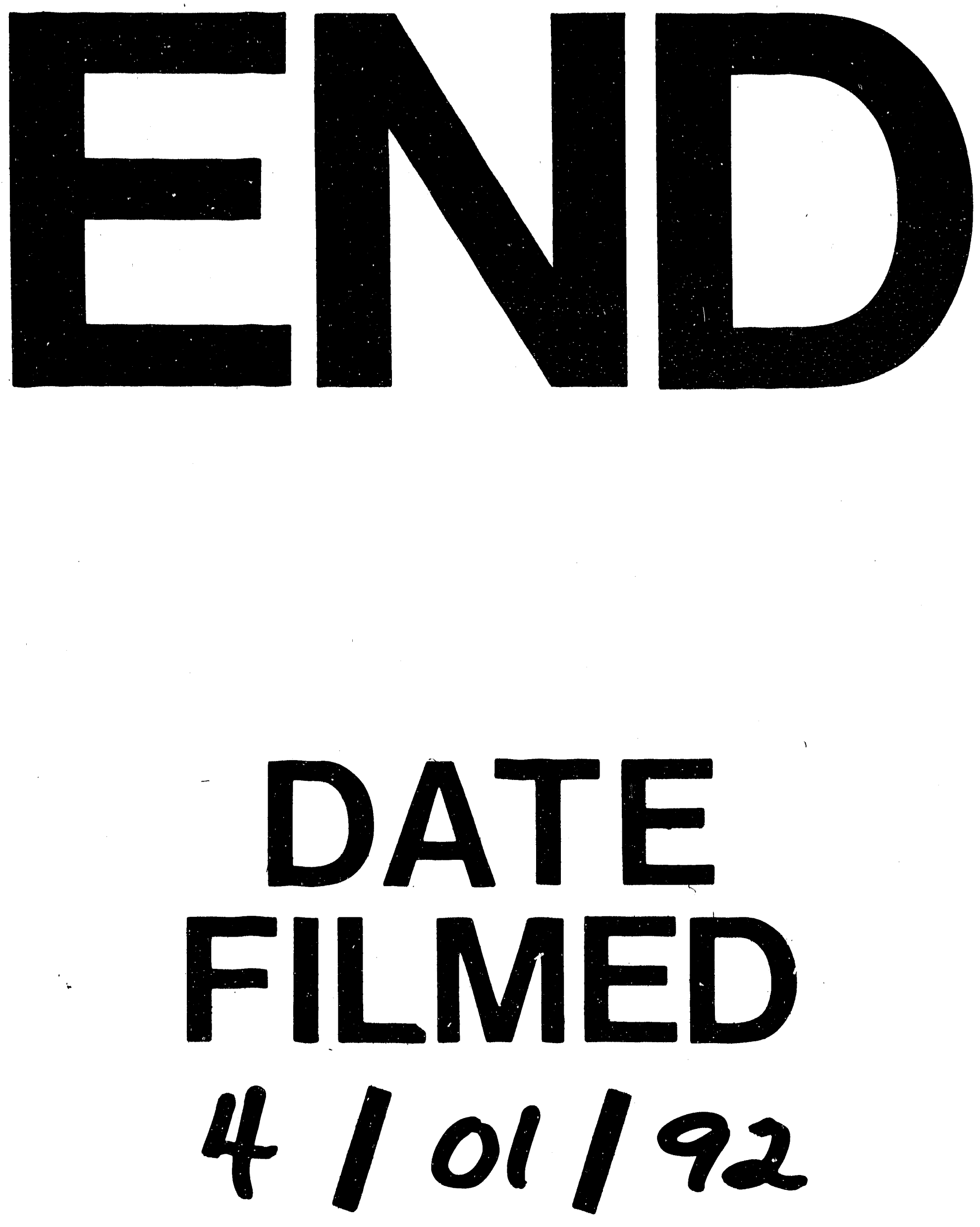

1 